\title{
HOW TO IMPROVE SOFTWARE QUALITY ASSURANCE IN DEVELOPING COUNTRIES
}

\author{
Ali Javed ${ }^{1}$, Muazzam Maqsood ${ }^{2}$ \\ KhurramAshfaqQazi ${ }^{3}$, Khurram Ali Shah ${ }^{4}$ \\ ali.javed@uettaxila.edu.pk, ${ }^{2}$ muazzammaqsood@yahoo.com \\ gemni1987@yahoo.com, ${ }^{4}$ syedkhuram84@gmail.com \\ 1,2,3,4 Department of Software Engineering \\ 1,2,3,4 University of Engineering and Technology Taxila, Pakistan
}

\begin{abstract}
Quality is an important factor in software industry. Software quality depends upon the customer satisfaction which can be achieved through applying standards. In this era achieving quality software is very important because of the high customer demands. Developed countries are excelling in software industry and improving day by day. Meanwhile developing countries like Pakistan are struggling with software quality and cannot maintain reputation in International Market. Software Quality lacks due to many reasons. This paper will address the problems for lacking interest in improving the software quality by higher authorities and software assurance team. We have provided solution to the addressed problems also.
\end{abstract}

\section{KEYWORDS}

Customer satisfaction, Reputation, Customer demands, Excelling.

\section{INTRODUCTION}

In this era quality is the most important factor in any kind of business. To achieve a respectable position in global market in IT industry [7], a company must have to produce very high quality products. Competition is very high and one cannot afford correcting errors after shipping the products to the customer.

A correction after shipping is very costly and it affects the Company credibility and organizations cannot afford losing Customers due to these kinds of problems. To avoid these problems, organizations should follow a proper quality management plan to remove errors from the products [6].Maintaining Quality for product is very important for Business Organizations as every Business Company is running towards automation [6]. Failure in real time software systems can have serious consequences.

The main role of SQA (software quality assurance) is to maintain the quality of the software products [9]. For that it is to make sure that the standards and procedures are properly followed. Software QualityAssurance [1] standards are developed to help organizations to achieve quality products [1]. Standards are the set of guidelines which help to achieve best results.

The standards and procedures include CMMI and ISO but it is difficult and costly for small SoftwareDevelopment Organizations to follow the standards. 
These software quality issues [2] are more prominent in developing countries like Pakistan. We have surveyed many highly ranked Software Solution providing organizations in Pakistan and interviewed many SQA employees.

The analysis of those interviews resulted in pointing out some critical problems which are degrading the software quality. We have also suggested that how to cope with these problems. Also suggested how the relationship between developers and QA team can be more cooperating and how team leads should react to some problems to solve it. Following our guidelines organizations can achieve high quality and can provide more customer satisfaction.

\section{LITERATURE REVIEW}

In this white paper, many issues related to quality are identified and many responsibilities of management are identified. Management plays a huge role in the SQA [11]. So it is the prime responsibility of the team managers to facilitate the team members and provide them the good working environment. There are many ways to improve the knowledge like they can go for some formal training courses. They should also take advantage of the seminars arranged by the different experts to improve their knowledge [4].

Quality plan is the most important in any quality improvement activity, SQA team managers are responsible and accountable to develop quality plan and also implement the plan. They are also responsible for quality measurement, quality improvement and configuration management.

Quality Plan includes the inspection of the problems. Inspection for finding the problems while maintaining the quality was explained by the Parnas [2]. The methodology used for inspection was dividing and conquer. It was time consuming task, but ensures problems detection. No training was required for the Testing Team or Software Engineers.

Parnas[2] explained the role of inspection in reducing quality problems in SQA [10]. First of all he explained the need of inspection in SQA [9] to reduce the problems, how it helps to find errors in the software. The main methodologies behind the inspection activity are dividing and conquer. The research also shows that inspection is a time consuming process but it ensures to find errors in the process.

The benefit of the inspection is to benefit errors in the code but it can also help to find many ambiguities in the development phase like it can easily reveal that proper guidelines are followed or not like commenting etc. it is not necessary to do inspection at the end of the project but it can be done at any phase of the project and reveal the errors from the code.

Quality effecting factors were explained in the research of David [16].That model explained that the quality of the free software is higher than the other projects.

To improve the quality [11] of the projects, PeerReviews plays very important role. This explains that user involvement is also very important for the feedback and on the basis of this feedback software quality can be improved very easily.

\section{RELATED WORK:}

Models relating to Software Quality Assurance are discussed below.

\subsection{PARNAS MODEL}

Parnas[2] explained the role of inspection in reducing quality problems in SQA. First of all he explained the need of inspection in SQA to reduce the problems, how it helps to find errors in the software. The main methodologies behind the inspection activity are dividing and conquer. 
The research also shows that inspection is a time consuming process but it ensures to find errors in the process.

Many benefits are the findings of this research; he explained that there is no formal need for the training of inspection. A software engineer does not necessarily need a certification for the inspection. As inspection does need a proper training so there is no need for a company to invest on it. So it will give many benefits despite consuming too much resources of a company. The key benefit of the inspection is to benefit errors in the code but it can also help to find many ambiguities in the development phase like it can easily reveal that proper guidelines are followed or not like commenting etc. it is not necessary to do inspection at the end of the project but it can be done at any phase of the project and reveal the errors from the code.

\subsection{DAVID MODEL}

David [16] explained in their research about the free software quality and factors affecting them. He explained that the quality of the free software is higher than the other projects. Many reasons behind the improved quality are explained in this research and some comparisons are done between free projects and other projects. The quality of this free software is high because of the open development models used in the development process.

\subsection{PEER REVIEWS MODEL}

Peer reviews plays very important role to improve the quality [11] of these projects, user involvement is also very important for the feedback and on the basis of this feedback software quality can be improved very easily. User gives their feedback on the basis of their experience and this feedback can help to improve the quality of the software.

\subsection{QUALITY FACTORS}

To find the quality factors and problem [14] areas for open source projects, in this research many interviews are conducted to find the answers. The interviews were unstructured and seven different open source developers gave the answers of these questionnaires. This research covers projects of very complex nature, questionnaires are distributed among all seven developers and then there answers were collected and findings were explained in the different categories. First category of the results is development and quality practices, here it is discussed that how infrastructure, processes and documentation problems can cause lack of software quality. All of the above mentioned areas are highly important factors for quality of the software.

\section{RESEARCH STUDY:}

To find the quality factors and problem [13] areas for open source projects, in this research many interviews are conducted to find the answers. The interviews were unstructured and seven different open source developers gave the answers of these questionnaires. This research covers projects of very complex nature, questionnaires are distributed among all seven developers and then there answers were collected and findings were explained in the different categories. First category of the results is development and quality practices, here it is discussed that how infrastructure, processes and documentation problems can cause lack of software quality. All of the above mentioned areas are highly important factors for quality of the software.

In second sections Quality problems are discussed. Some major quality issues discovered by the research are coding issues, configuration management, security, bug reporting issues, volunteers attracting, communication problems and documentation issues. With the help of this 
research, many quality aspects are identified which can cause problems for free software development.

Our research spans to eight highly professional and competitive organizations in Pakistan. We conducted interviews of highly skilled and experienced professionals from those organizations and then the critical areas [14] are identified as a result of a very keen analysis. Distribution of companies surveyed in three major categories is shown in figure 1 .There are $50 \%$ companies which are purely software development companies while Software consultant companies and telecommunication companies included in the survey are $25 \%$ each.

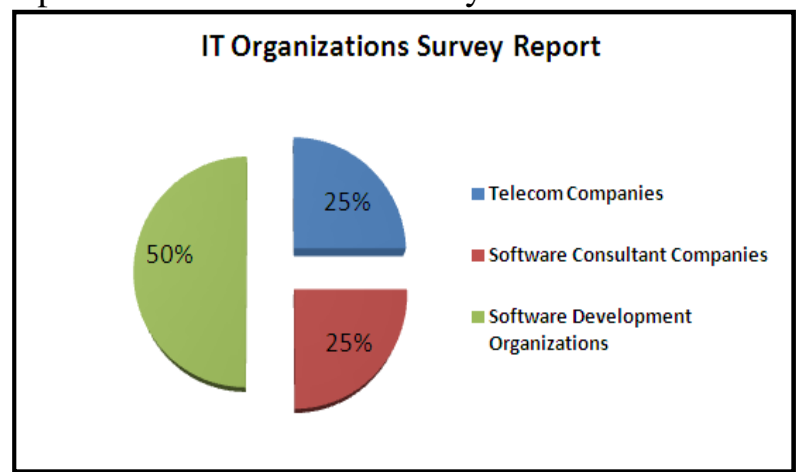

Figure.1 IT Organization Survey Report

Distribution of interviews is divided in three major categories and shown in figure 2.

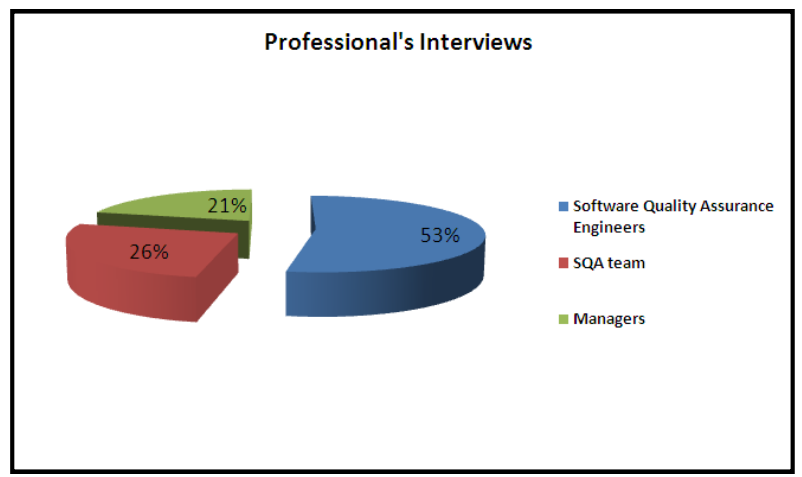

Figure 2 Personal's Interviews

Interviews include 53\% Software Quality Assurance Engineers, 26\% SQA team leads and 21\% managers. The main issues addressed in this research contains

- Time

- Budget

- Less use of quality standards

- Lack of specialists

- Project durations

- Compromise on quality due to less profit

- Developer's attitude

- Team formation for requirements gathering

- Politics 


\subsection{CRITICAL ISSUES}

Software industry is struggling in developing countries like Pakistan. There are many reasons behind that, some of those reasons [2] are pointed out here. As figure 3 shows these critical issues have a very severe impact on the companies mentioned in the survey.

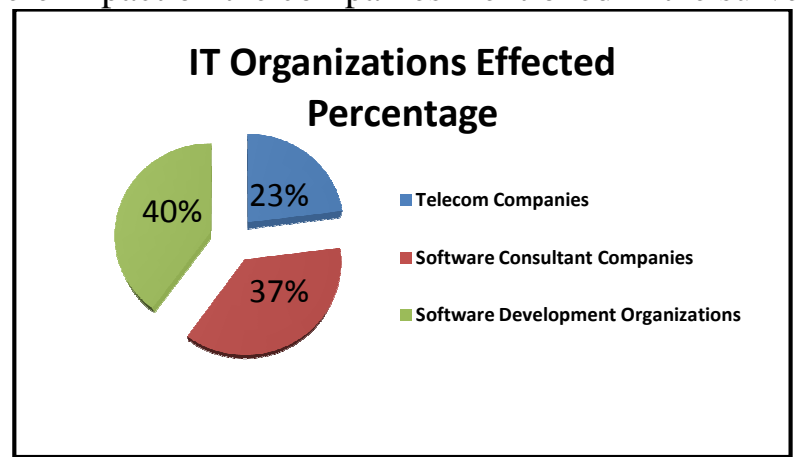

Figure. 3 IT Organization Effected Percentage

\subsubsection{LACK OF SPECIALISTS:}

Mostly software organizations in developing countries don't have a proper SQA team or testers. In small software organizations usually a developer is also fulfilling the responsibilities of tester which is one of the main reasons of lack of software quality. Developer is mostly ineffective when he is reviewing his own code. It will reduce quality and maintainability. On many occasions, small organizations just test the functionality of the software and deliver it to the customer. By doing so they save some cost [8] but mostly, the quality of the software is not up to the mark.

Figure 4 also shows that specialists are also very important and $85 \%$ losses in SQA are due to lack of skilled professionals.

\subsubsection{LACK OF CONFORMANCE TO STANDARDS:}

In small Software Organizations, if they have a SQA team then they are not following SQA standards like CMMI. As CMMI is a dedicated software quality assurance model but due to lack of highly skilled specialists, experts and resources like time and budget, this model is not usually followed which ultimately results in a bad quality software products in developing countries. On many occasions small organizations just develop the software without even following any standards to save the cost but that can lead to failures which can cost even more than that.

\subsubsection{DEVELOPER'S ATTITUDE:}

Developer's behavior at times can be an issue for SQA team. One issue which mentioned by many SQA employees is that, developers mostly do not show cooperating behavior. On many occasions developer does not show interest in the problem areas mentioned by the SQA [10] team. Developer's mostly answer the SQA team with the same logic that they SQA [9] team don't have proper domain knowledge. So what I have done is right.

As developer's attitude is an integral factor of environment, figure 4 show it has an important influence in software industry. 


\subsubsection{UNREALISTIC DEADLINES:}

Time duration is also an important problem factor for quality of software. Mostly QA team has very tight schedule to deliver the project. Half ofthe total timeis mostly spent on domain understanding and functional requirements.

As domain knowledge is the most important factor for QA team. If they lack in domain knowledge then it will affect quality quite badly. If a tester could not understand the domain knowledge properly then they can't find errors in the system or possibly they find a wrong mistake in the system.

That is why most of time is spent in understanding domain knowledge, then they left with very little time for testing and ultimately they can't lead to proper testing. It is shown in the figure 4 that research results reveal that $60 \%$ projects fail due to unrealistic deadlines.

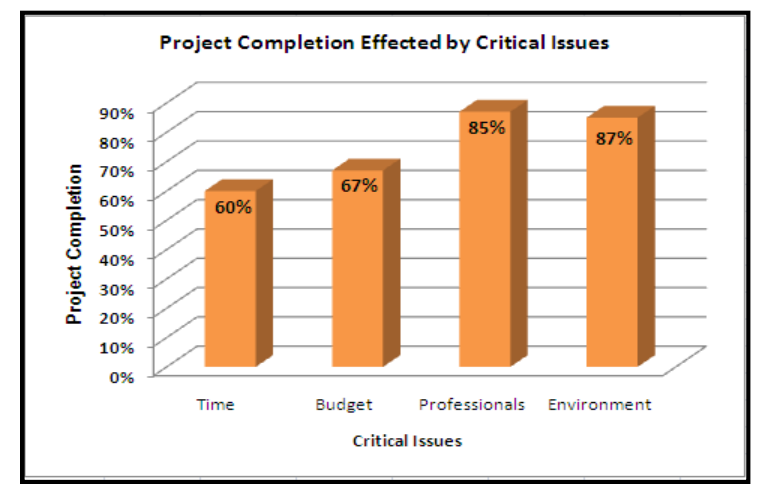

Figure 4 Project Completion Effected by Critical Issues

\subsubsection{TEAM FORMATION AND COMPROMISE ON QUALITY:}

Team formation for the requirements gathering is also very critical. Mostly there is no SQA [17]representator in the requirements team. This leads to lack of domain knowledge and functional requirements. Compromise on quality is another problem area for lack of software quality in developing countries due to lesser profit margins. Most of the time project managers ask their QA team members to concentrate more on those projects where they can earn more profit. Profit margins are high for the foreign projects and foreign client demands very high quality. So team managers spend most of the time on foreign projects because they don't want to lose those clients. This approach affects the quality of the local projects.

In Pakistan, QA team leads also compromise on quality of local projects because they consider Pakistani clients technically less strong as compared to foreign clients and consider that local clients mostly does not go for third party testing but foreign clients hire a third party to evaluate the quality of the projects. That's why mangers give less time to the testing and QA activities of the local projects.

\subsubsection{INTERNAL POLITICS:}

Politics is also another important issue behind the lack of software quality. Leg pulling is a big factor in developing countries not only in IT industry but in every field. Different team leads in the department try to use theirinfluence on higher authorities to get highly paid projects. So the team leads with better Public Relations get highly paid projects which affect the experience and the benefits for their team members. 
Figure 4 shows that how, many critical factors like time, budget, professionals and environmental hurdles like politics, compromise on quality due to profit margins and developer's behavior affect the software quality. Research results in the form of percentage are shown in the graph.

\section{RESOLVING ISSUES}

Some solutions are suggested on the basis of our survey and interviews. These guidelines are based on the experience of SQA team leads from the leading Software Development Organizations of Pakistan which are ranked on CMMI level 4 and level 5.With the help of our research, different procedures and standards are closely observed in highly ranked organizations, guidelines on the basis of this analysis are provided which can help individuals and software organizations to improve the quality of their software products.

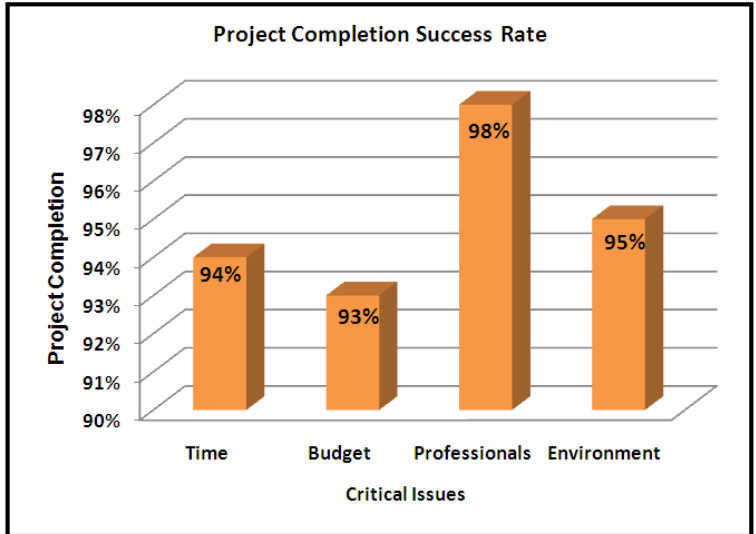

Figure 5 Project Completion Success Rate

These guidelines can also be very useful for those organizations which are already developing high quality software products because these guidelines can also be very useful to maintain the quality of the software products.

As figure 5 shows, by adopting these guidelines, software success rate has improved drastically. If these guidelines are implemented properly to solve Time (Deadlines), budget, skilled professionals and environmental factors. Then on average it increases the success rate up to $95 \%$.

\subsection{DEPLOYING CMMI MODEL:}

CMMI is a set of dedicated standards and procedures which is very helpful to achieve quality. Even though it takes lot of resources and time to follow the CMMI standards but at the end it surely improves the quality of software products. Using CMMI also improves the reputation of the software organizations because mostly customers inquire aboutCMMI certification and CMMI level. It takes money and time to implement CMMI standards but in the long run it improves the quality of software products as well as the reputation of the company. This helpsin gaining a respectable position in Global market. So it is highly recommended to follow CMMI standards. 


\subsection{CERTIFIED AND SPECIALLIZED SQA TEAM:}

It is highly necessary for any software company to have a proper SQA team or at least full time tester because only a tester can find the errors and can match the specifications with the user demands and give an unbiased opinion to improve the quality of the software. If a coder is reviewing his own code then it is less likely for him to find all the errors. The job of the SQA team is to make sure that all the procedures are followed and to minimize the errors in the product. That's why it is necessary to have a proper and fully functional SQA team in the software company to improve and maintain the quality of the software.

Another important factor here is a good recruiting process of the organizations. On the first place hire very competitive employees and then develop their professionalism through training and mentoring.

It is also the responsibility of the higher authorities to create an environment where team members always work for the best quality products. Mold the newly hired employees in such a way that they don't compromise on quality in any condition.Certifications to improve the skills are also very important for the team members. Invest on the technical certifications of your employees. It can earn you a lot profit in the long run.

\subsection{DEVELOPER'S ATTITUDE:}

Mostly there is a big issue related to the relationship between developers and SQA team. Many SQA teams complain about the developer's behavior and according to survey and interviews of the different team leads.It is suggested that managers should make sure to develop a good relationship between development team and SQA team because both are the integral part of the quality improvement.

Developer's attitude can be improved by the training sessions and workshops held by the management. In these workshops, highly professionals from the organization teaches that how to improve their abilities and approach towards the different team members.

Monthly meetings can also be very helpful for the team environment. In this way team members can be gelled together on monthly dinner or meeting. These informal activities will help to improve the relationship between different teams and they will cooperate with each other on different issues. This will help the organization.

So it is the duty of the manager and team leads to handle the issues and improve the working relationship between SQA and development team.

\subsection{GRIP OVER DOMAIN KNOWLEDGE:}

Many times SQA teams could not understand the domain knowledge of the Software and find hard to give high quality software. To solve the domain knowledge issue, there should be a SQA representation in the requirements gathering team. It will help the SQA team to properly understand the domain knowledge. It will have two benefits, firstly SQA representative can give a list of potential problems to the developer that has probability of occurrence during the project and in this leads to reduce errors and enhancement in software quality.If SQA team have a prior knowledge of domain that can deliver even in a very tight schedule because they won't waste their time in understanding the domain and functional requirements. So that time can be saved and project can be delivered on time. On the other hand, It is the responsibility of the team lead to accept only feasible deadlines and defer non feasible. 


\subsection{NO COMPROMISE ON QUALITY:}

In developing countries it is a common practice to focus on those projects which are strong in business prospective and compromise on the local projects. Some of the highly ranked software houses SQA teams are working on foreign projects while some are working on local projects.

SQA teams which are working on foreign projects are getting more benefits than the others and their salaries are usually higher than the other colleagues. The reason behind the difference is the profit margins. That adds more pressure on team leads working on local projects and this results in compromise on quality because they want to spend less time on projects. So that they can work on more projects to show efficiency, in order to make good quality products team leads should make sure to give proper time to every project regardless of the profit margin.

It is the responsibility of the higher management to make sure that quality is maintained for every project and gives equal benefits to all teams regardless of the foreign project factor. A very highly ranked software company in Pakistan has decided not to work on local projects recently just because of this issue, which is a better option if you can't handle the quality issue created because of profit issues.

\subsection{AVOID INTERNAL POLITICS:}

One can't deny the politics factor in any field so as in software field but it is the responsibility of the managers to make sure that politics should not affect the quality of the software. Professional jealousy is good but it must not affect the reputation of the company.

\section{SIMULATION}

Our research work simulation was on already developing projects. We have first observed errors and problems on the projects that were in the deploying stage. Then we have implemented our proposed ideas on developing projects and observed the results. According to our research most influencing factors are lack of specialists, lack of domain knowledge, internal politics and non-certified team.

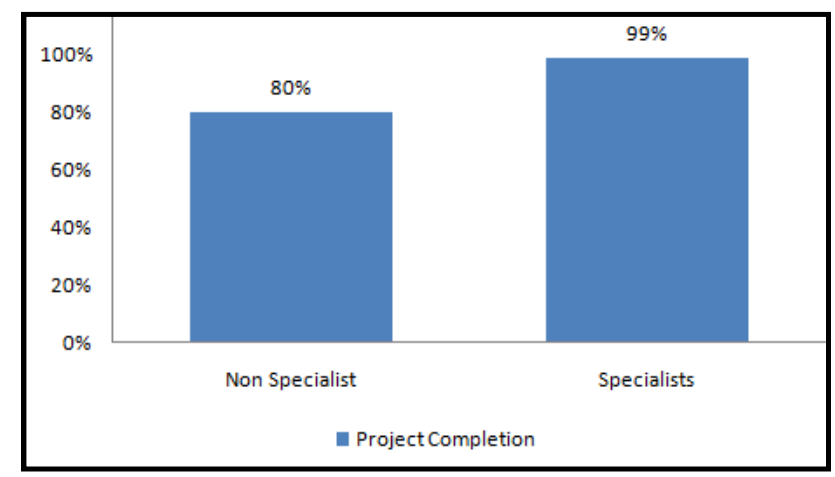

Figure 6 Effects of Non Specialists on Project Completion Rate

Then we guided some of the development teams to improve these issues and by improving these issues the success rate improved. As explained in the fig[6], when the specialists were chosen for the right job then project competition rate goes to $99 \%$. Specialists know exactly how to tackle different problems in the project life cycle. 
Advanced Computing: An International Journal ( ACIJ ), Vol.3, No.2, March 2012

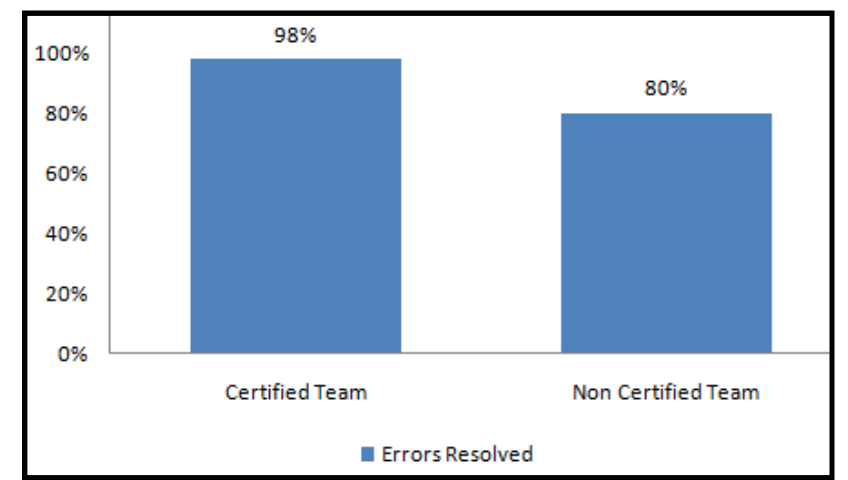

Figure 7Effects of Certified Team on Project Completion Rate

Certifications are also an important factor in the software quality assurance. By spending more money on the certifications of your employee companies' reputation gets improved. So by choosing the certified team for the projects, completion ratio improves by almost $98 \%$. Certifications give more exposure to the employees towards new technologies. Fig[7] shows the results improvement.

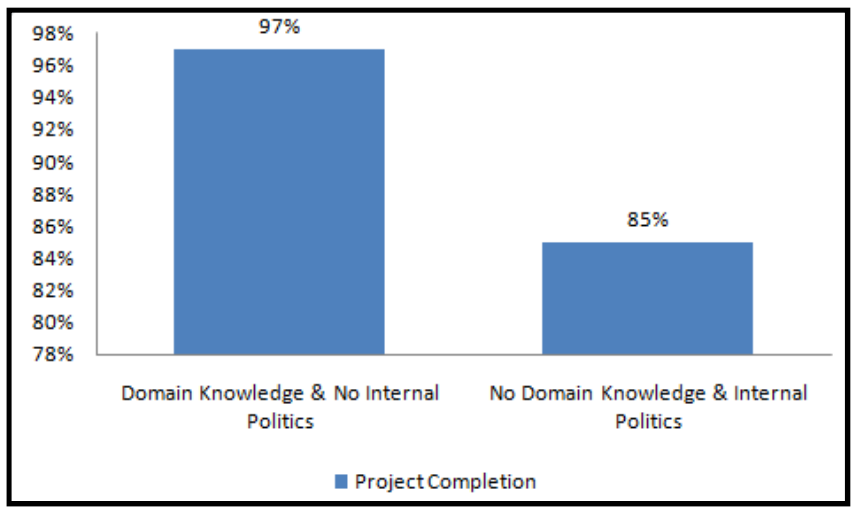

Figure 8Effects of Domain Knowledge and politics on Project Completion Rate

As shown in the fig[8], Domain knowledge was another major hurdle in the completion of the projects. So by improving the domain knowledge of the team members by giving them proper time to understand the requirements improves the completion rate of the projects under study. Another major issue handled was internal politics, managers make sure to avoid any conflicts between team members and SQA team. So in this way $97 \%$ completion rate was achieved as compared to $85 \%$.

Our suggestions to improve quality really helped in the completion of projects and quality of the software's also improved because the number of errors was quite less than before.

\section{CONCLUSION:}

In this research SQA problems are identified and solutions are suggested to cope with those problems and improve the software quality. Software organizations can only get a respectable position in Global Market if they concentrate on quality. SQA plays a very important role in business of Software Company because the only factor which results in getting consistent projects from permanent customers is customer satisfaction. Big and reputed Organizations can 
hire you permanent vendor for their Software / IT Solutions while getting good and quality products and delivered in time.

\section{REFERENCES}

[1] Agarwal, R. ; Nayak, P. ; Malarvizhi, M. ; Suresh, P. ; Modi, N. "Virtual Quality Assurance Facilitation Model" Global Software Engineering, 2007. ICGSE 2007. Second IEEE International $\begin{array}{llll}\text { Conference } & \text { on } & 27-30 & \text { Aug. }\end{array}$ [2] Jani, Hajar Mat "Applying Case-Based Reasoning to software requirements specifications quality analysis system"Software Engineering and Data Mining (SEDM), 2010 2nd International Conference $\begin{array}{llr}\text { on 23-25 } & \text { June } & 2010\end{array}$

[3] Hansson, J ; Lewis, B ; Hugues, J ; Wrage, L ; Feiler, P ; Morley, J "Model-Based Verification of Security and Non-Functional Behavior using AADL"Security\& Privacy, IEEE on 30 October 2009

[4] Koru, A.G. , Dongsong Zhang, El Emam, K. , Hongfang Liu "An Investigation into the Functional Form of the Size-Defect Relationship for Software Modules" Software Engineering, IEEE Transactions on March-April 2009

[5] Kayes, M.I. "Test case prioritization for regression testing based on fault dependency" Electronics Computer Technology (ICECT), 2011 3rd International Conference on 8-10 April 2011

[6] Zheng Yan , Prehofer, C. "Autonomic Trust Management for a Component-Based Software System" Dependable and Secure Computing, IEEE Transactions on Nov.-Dec. 2011

[7] Biffl, S. ; Halling, M. "Investigating the influence of inspector capability factors with four inspection techniques on inspection performance"Software Metrics, 2002. Proceedings. Eighth IEEE Symposium on 07 August 2002

[8] Rubey, R.J. ; Browning, L.A. ; Roberts, A.R. "Cost effectiveness of software quality assurance" Aerospace and Electronics Conference, 1989. NAECON 1989., Proceedings of the IEEE 1989 National on $22-26$ May

1989

[9] Boehm, Barry , Chulani, Sunita , Verner, June , Wong Bernard "Fifth Workshop on Software Quality" Software Engineering - Companion, 2007. ICSE 2007 Companion. 29th International Conferenceon 20-26 May 2007

[10] Yau, S.S. , Wang, Y.-W. , Huang, J.G. , Lee, J.E. “An integrated expert system framework for software quality assurance" Computer Software and Applications Conference, 1990. COMPSAC 90.Proceedings., Fourteenth Annual International on 31 Oct-2 Nov 1990

[11] Hribar, L. , Burilovic, A. , Huljenic, D. "Implementation of the Software Quality Ranks method in the legacy product development environment" Telecommunications, 2009. ConTEL 2009. 10th International Conference on 8-10 June 2009

[12] Munch, J. "Risk Management in Global Software Development Projects: Challenges, Solutions, and Experience" Global Software Engineering Workshop (ICGSEW), 2011 Sixth IEEE International Conference on 15-18 Aug. 2011

[13] Huai Liu , Fei-ChingKuo, TsongYueh Chen "Teaching an End-User Testing Methodology"Software Engineering Education and Training (CSEE\&T), 2010 23rd IEEE Conference on 9-12 March 2010

[14] Catelani, M. , Ciani, L. , Scarano, V.L. , Bacioccola, A. "A Novel Approach To Automated Testing To Increase Software Reliability" Instrumentation and Measurement Technology Conference Proceedings, 2008. IMTC 2008. IEEE on 12-15 May 2008.

[15] Catal, C. , Diri, B. “A Conceptual Framework to Integrate Fault Prediction Sub-Process for Software Product Lines" Theoretical Aspects of Software Engineering, 2008. TASE '08. 2nd IFIP/IEEE International Symposium on 17-19June 2008

[16] Glick, B. “An SQA quality tracking methodology"Software Maintenance, 1990., Proceedings. Conference on 26-29 Nov 1990 
Advanced Computing: An International Journal ( ACIJ ), Vol.3, No.2, March 2012

Engr. Ali Javedis a PhD Scholar in Department of Computer Engineering at University of Engineering \& Technology Taxila. He has been a lecturer since April 2008 in the Department of Software Engineering, University of Engineering and Technology Taxila, Pakistan.He has received his master's degree in Computer engineering from university of Engineering and Technology Taxila, Pakistan in February, 2010. He graduated from University of Engineering and Technology taxila in Software Engineering in September 2007. His areas of interest are Video

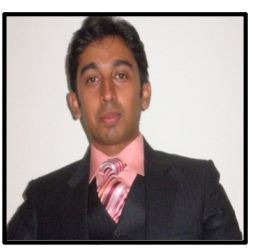
Summarization, Digital Image Processing, Computer vision, Software Quality Assurance, Software testing, Software Requirements Analysis and Mobile application development.

Engr. MuazzamMaqsoodis MSScholar in Department of Software Engineering at University of Engineering \& Technology Taxila. He holds a Bachelor's degree in Software Engineering from University of Engineering \& Technology Taxila and has performed exceptional on his 4-year program. He has a keen interest in Software quality assurance, Software Project management and Video Summarization. Muazzam has been striving to bring innovations in the said fields

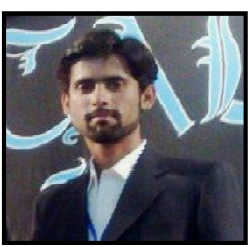
through his research. A notable example is his research related to Software Quality Assurance which is aimed to aiddifferent managers and team leads to solve the Software quality assurance issues.

KhurramAshfaqQazi is MS Scholar in Department of Software Engineering at University of Engineering and Technology, Taxila, Pakistan. He has done his B.Sc Software Engineering from University of Engineering and Technology, Taxila, Pakistan. He has a great research work on Noise Removal Algorithms in Image Processing. In 2008 he stayed in National Database and Registration Center to Study finger print or thumb impression image processing. In 2009, he has worked in Software Organizations in R\&D Department. He has research work

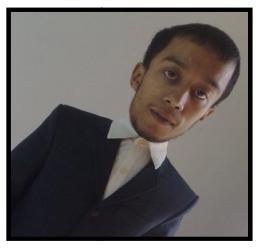
in Improving Quality of Software Products and improving development techniques. During 2010, he has worked in improving products quality relating to medical. During 2011 and 2012, he has taken keen interest in research work relating to Project Management, Advance Software Technologies and Improving and Implementing Logical Algorithms. Currently, Khurram is working as Lab Engineer in Department of Software Engineer, University of Engineering and Technology, Taxila, Pakistan.

Engr. Khurram Ali Shah is MSScholar in Department of Software Engineering at University of Engineering \& Technology Taxila. He has done his Bachelor's degree in Software Engineering from University of Engineering \& Technology Peshawar and has performed exceptional on his 4-year program. He has a keen interest in Software Project management, Software quality assurance and Computer Networks. Khurram has also worked in a software house in the department of Quality Assurance. His work experience is reflected in his research

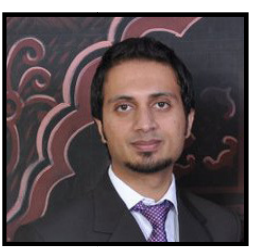
papers. One of his important researches includes IT project management where he has depicted the practical issues faced in the industry. 